\title{
INICIOS DE LA MICROBIOLOGÍA ENOLÓGICA GALLEGA $^{1}$
}

\section{THE BEGINNING OF GALICIAN WINE MICROBIOLOGY}

\author{
ALFONSO V. CARRASCOSA ${ }^{2}$ \\ Dpto. Microbiología, I. de Fermentaciones Industriales, CSIC
}

\begin{abstract}
Resumen
Se cumplen 70 años de la creación del Consejo Superior de Investigaciones Científicas (CSIC), donde se llevó a cabo la institucionalización de la ecología y se dio un fuerte impulso a la investigación en microbiología y biotecnología. Es poco conocido que parte de este esfuerzo fue finalmente aplicado a la enología, cristalizando en la Teoría Ecológica del Vino. Los primeros estudios científicos de microbiología enológica gallega fueron realizados en el Departamento de Microbiología del Instituto de Fermentaciones Industriales del CSIC (IFI-CSIC) en la década de los 70, y formaron parte de las evidencias que sirvieron para establecer dicha teoría. Instalaciones inadecuadas, unidas al empleo masivo de fungicidas y sulfuroso como antisépticos, fueron identificados como posibles
\end{abstract}

\begin{abstract}
The Spanish Council for Scientific Research (Consejo Superior de Investigaciones Científicas, CSIC) was created 70 years ago, and is considered the biggest research institution of Spain. The process of the institutionalization of Spanish ecology has been made in its dependences, during an important growing of Spanish microbiology and biotechnology. There is a bad known fact that a part of this effort were finally focused to the enology, giving the Ecological Wine Theory. The first studies made with this purpose about the Galician wine microbiology were carried out in the Institute of Industrial Fermentations (Instituto de Fermentaciones Industriales, IFI-CSIC) in the 70 decade, and were a part of the evidences taking into account to elaborate the Theory of Ecological Wine. The abusive employment of fungicides and
\end{abstract}

${ }^{1}$ Recibido/Received 3.08.2009. Aceptado/Accepted 30.11.2009

2 Se agradecen las ayudas con los proyectos de investigación 25506 FUN C FOOD; CONSOLIDERINGENIO 2010; AGL2006-02558 y ALIBIRD-CM S-0505/AGR-0153. 
causas de los problemas detectados durante el estudio de la vinificación. Finalmente se recomendaría como idóneo para salvaguardar el tipismo de los vinos gallegos, y reducir al mínimo el empleo de dióxido de azufre, la inoculación secuencial de los mostos con las levaduras que fueron aisladas en el estudio y que todavía se conservan en el IFI-CSIC. En este artículo se presentan los resultados de esos estudios, sus consecuencias, y la situación en la que se encontraba la microbiología enológica española en esos momentos.

\section{Palabras clave}

Galicia, microbiologia enológica, CSIC, Teoría Ecológica del Vino sulphur compounds to control the microbiology of the winemaking was considered by this theory a practice that eliminate the possibility of growing of several yeast species to develop their metabolism to give desired sensorial characters to the wine. By this reason, the employment of selected and wild authochtonous yeast strains, isolated from Galician musts and wines and progressively inoculated, were recommended to avoid the use of the chemical compounds like sulphur dioxide and fungicides, and to preserve the typical Galician wine characteristics. Two scientific articles made in 70 decade are commented, and also the conclusions given by the authors in relation with the Theory of Ecological Wine, and with the situation of Spanish wine microbiology at this moment. The isolated yeast during these studies are conserved till now in the Dept. of Microbiology of the IFI-CSIC.

\section{Keywords}

Galicia, wine microbiology , CSIC, Theory of Ecolgical Wine 


\section{EL VINO Y EL NACIMIENTO DE LA MICROBIOLOGÍA}

El vino tuvo mucho que ver con el nacimiento de la microbiología como disciplina científica, ya que fue estudiando el vino como el genial químico francés, Louis Pasteur, demostró la existencia de las levaduras y su protagonismo en dicho proceso. Lo describió en 1857 en su famoso estudio Mémoire sur la fermentation alcoolique. A partir de aquí elaboró la teoría del origen microbiano de las enfermedades infecciosas, propiciando el principio del fin de los devastadores efectos que venían teniendo sobre el devenir de la humanidad los microbios patógenos.

El desarrollo posterior de la nueva disciplina científica en España comenzaría a finales del siglo XIX muy relacionado con la denominada medicina de laboratorio, que propugnaba el uso del microscopio para el estudio de las enfermedades infecciosas. La enseñanza de la nueva disciplina científica se integraría en las de higiene, impartidas en las cátedras de Anatomía Patológica de las Facultades de Medicina, que incluirían unas prácticas de bacteriología a principios del siglo XX. Los establecimientos como éstos, en los que existían microscopios, han sido propuestos como los primeros en trabajar en microbiología. También un médico, Luis del Río y Lara, escribiría el primer libro en español de microbiología titulado "Elementos de microbiología para uso de estudiantes de medicina y veterinaria" (1898), y otro importante médico, Jaime Ferrán, sería quien más artículos científicos sobre la especialidad publicaría en el último cuarto del siglo XIX.

\section{INICIO DE LA MICROBIOLOGÍA ENOLÓGICA}

Del ámbito médico, la microbiología pasó al enológico de la mano de quien fuera vicepresidente del CSIC, pionero e institucionalizador de la microbiología enológica, el ingeniero agrónomo Juan Marcilla Arrazola (1886-1950), que fue además el primer presidente de la Sociedad de Microbiólogos Españoles, fundada en 1946, que llegaría a denominarse con el tiempo Sociedad Española de Microbiología. Marcilla llevó a cabo el primer estudio científico en la modalidad, describiendo la formación de velo -desarrollo profuso en la superficie- por levaduras en vinos andaluces de alto grado alcohólico. También con Marcilla, y en la ampliación de dicho estudio, colaboró la primera ingeniera de España, que además es considerada también la primera enóloga, Isabel Toran del Carre.

Existe una clara conexión entre Marcilla y los primeros estudios de microbiología enológica gallega que se comenta a continuación. Dentro del panorama de la microbiología enológica europea de su época, comenzaba a destacar el enfoque 
abordado por los microbiólogos italianos, concretamente la denominada Escuela de Microbiologia de Perugia (ubicada en el Istituto di Microbiologia Agraria e Tecnica dell'Universita di Perugia), que se interesaron por describir la realidad especiológica de las levaduras de sus caldos para emplear levaduras seleccionadas en las fermentaciones vínicas. Y es que son precisamente las levaduras los microbios que transforman el mosto de uva en vino, gracias a la capacidad que tiene de originar la transformación de los azúcares en etanol, mediante la transformación metabólica conocida con el nombre de fermentación alcohólica. Gracias a dicha transformación, las levaduras obtienen energía, imprescindible para su crecimiento y multiplicación.

Marcilla, sensible a todos los adelantos y nuevos desarrollos en materia de microbiología enológica, señalaba para España en su obra magna "Tratado de viticultura y enología españolas" (1942) que se constataba “...aún el muy escaso conocimiento que poseemos acerca de la flora microbiana espontánea en los mostos de uva de cada comarca vitícola". Reconociendo los límites de la microbiología, aun en perjuicio propio, admitía que “...Los especiales gustos y aromas, las calidades todas de un vino dado, ¿pueden ser obtenidas con una sola clase de levaduras puras o son más bien el resultado que deriva, inicialmente y en parte, de una fermentación mixta producida por dos o más especies o razas?" para contestar con la clave que permite entender el posterior trabajo del grupo del Prof. de Investigación Dr. Baldomero Iñigo Leal en el Dpto. de Microbiología del IFI-CSIC en los estudios sobre el que versa este articulo, continuaría Marcilla diciendo " Creemos que jamás se podrá contestar a esta pregunta con carácter de generalidad. Es casi seguro que para muchos vinos comunes bastaría con una levadura pura, ...pero para los Chianti italianos autoridades como nuestro colega y amigo el prof. Castelli (T.) dudan mucho que puedan ser obtenidas las mejores y más típicas calidades con una sola levadura pura, y es seguro que lo mismo ocurrirá para muchos vinos finos españoles y extranjeros”. El esfuerzo científico llevado a cabo en el IFICSIC se desarrollaría en parte como búsqueda de la respuesta a esa pregunta, y en sus inicios precisamente de la mano del mencionado microbiólogo italiano, el Prof. Tomasso Castelli.

Con ocasión del Congreso Internacional de Industria Agraria, celebrado en Madrid en el año 1954, Castelli expuso los resultados más relevantes de sus estudios microbiológicos, causando muy buena impresión en Marcilla, que a la sazón era director del Centro de Investigación Enológica del Patronato Juan de la Cierva del CSIC. Marcilla creó la beca que Iñigo ganó para trabajar con Castelli. El primer estudio científico que realizaron fue en los vinos manchegos y, con el paso del tiempo y con sus colaboradores del IFI-CSIC, el de los vinos gallegos. 


\section{PLAN DE TRABAJO DEL ESTUDIO SOBRE LA FERMENTACIÓN VÍNICA EN GALICIA}

El objetivo fundamental del que podría considerarse el primer estudio científico sobre microbiología enológica gallega, viene descrito en su introducción: "En los caracteres organolépticos de un vino influyen, además de factores edafológicos, botánicos y climatológicos, la diversidad de levaduras que intervienen en la fermentación espontánea de los mostos. Por tanto, se deberían utilizar para la fermentación controlada de los mostos las mejores levaduras que se desarrollan en cada zona".

La denominada fermentación espontánea del mosto es aquella que ocurre tras la obtención del mismo mediante la operación denominada estrujado, en la que la uva proveniente de la vendimia es sometida mediante la estrujadora a una presión suficiente para que libere el mosto de la pulpa, pero inferior a la necesaria para aplastar las pepitas de la misma, lo que produciría alteraciones organolépticas, es decir, sensoriales en el vino resultante. Las levaduras que llevan a cabo la fermentación espontánea están tanto en la superficie del grano de uva, como en la de las instalaciones de la bodega, debido a la ubicuidad propia de los microbios.

El mosto obtenido mediante el estrujado, inmediatamente inoculado por las mencionadas levaduras que quedan suspendidas en el mismo, es introducido en las cubas o depósitos de fermentación. Fue durante la misma cuando se aplicaron técnicas microbiológicas sobre las levaduras espontáneas para "aislarlas, identificarlas y llevar a cabo un estudio de sus características, orientado a la posible selección de las más idóneas". Terminado todo el trabajo, se podría disponer de una colección de levaduras autóctonas de las comarcas estudiadas que, una vez seleccionadas, servirían para ser inoculadas en los mostos de años consecutivos, asegurando así la presencia de cepas idóneas para la vinificación típica de la región, para realizar de este modo la fermentación inducida o controlada, frente a la espontánea, que era la que se aplicaba mayoritariamente en la época del estudio en Galicia.

Fueron tomadas 23 muestras de mosto durante vinificaciones llevadas a cabo en las comarcas de El Ribeiro (Orense) y Albariño (Pontevedra), en bodegas de las localidades de Barral, San Cristóbal, Leiro, Arnoya, Layas, Albariño, Sangenjo y Villagarcía de Arosa (Figura 1). En el artículo se hace una descripción de las características abióticas de la zona, tanto en materia de los tipos de suelo (edafología), fundamentalmente provenientes de la descomposición granítica, como de la climatología, típicamente atlántica, húmeda, con una pluviometría anual de $1500 \mathrm{~mm}$. Las variedades de vid (Vitis vinifera) de uva blanca cultivadas en la región estudiada eran principalmente las de treixadura, jerez, torrontés, godello, macabeo, albilla, 
loureira y albariño. Las de uva tinta, garnacha, ferrón, sousón, mencía, tempranillo, caiño y brancellao.

Todo el estudio microbiológico se desarrolló mediante una sistemática general preestablecida previamente por Castelli y practicada por la Escuela de Perugia, basada en la técnica de identificación de la Escuela Holandesa de Kluyver, asumida y mejorada por el grupo del IFI-CSIC. Las muestras se tomaron recién obtenido el mosto, denominándose esta primera muestra, primera fase o I, que corresponde al mosto sin fermentar. La segunda o II correspondería con la fase de fermentación tumultuosa del mosto, a los siete días de la primera, y la última a los veinte días de la primera, denominada III y tomada tras terminar la fermentación tumultuosa. Las muestras fueron recogidas en las bodegas más representativas de la región gallega, en recipientes estériles, para no contaminarlas con microbios ajenos a la fermentación.

De cada muestra se realizó una vez cultivadas en medio sólido de gelatina(agente solidificante)-mosto(nutrientes), el aislamiento de tres colonias de levadura, que serían conservadas para su caracterización posterior en medio sólido agar (agente solidificante)-malta(nutrientes).

En esta época se aplicaban métodos de estudio fenotípicos con un fuerte componente morfológico, tanto macro como microscópico, aun cuando las técnicas moleculares ya se habrían paso en la taxonomía microbiana. Se iniciaba el estudio con la observación microscópica de las levaduras aisladas y conservadas, anotándose la existencia o no de ramificaciones pseudomiceliares, y la formación o no de esporas. Macroscópicamente se estudiaba la morfología de las colonias de levadura cultivadas en agar malta y en medio líquido de mosto de uva. A partir de aquí se iniciaban las pruebas bioquímicas de asimilación de sustancias nitrogenadas, la fermentación de azúcares, el desarrollo en presencia de etanol, la escisión de la arbutina, la asimilación de azúcares, asimilación de sustancias hidrocarbonadas, hidrólisis de la rafinosa, así como pruebas más enológicas tales como el estudio del poder fermentativo o capacidad de producir etanol a partir de azúcar, la producción de acidez volátil y la producción de velo.

\section{LOS AGENTES DE LA FERMENTACIÓN VÍNICA EN LA REGIÓN DE GALICIA}

En el estudio realizado fueron aisladas 303 cepas de levadura, 99 de la primera fase fermentativa, 105 de la segunda y 99 de la tercera. Se constató un hecho interesante, cual es la lentitud en la cinética fermentativa, y por ello, la larga duración 
de la fermentación del mosto. La explicación dada fue de una parte la escasa micropoblación epifítica, es decir, adherida la superficie de la piel de la uva, debido a las abundantes lluvias previas a la vendimia y al probable uso masivo de funguicidas, utilizados para evitar la degradación excesiva de la uva por el ataque de los mohos, pero dañinos para el desarrollo de las levaduras de fermentación. Otra observación peculiar fue la de la existencia de un poder fermentativo en las levaduras aisladas inferior al habitual en otras zonas vinícolas ya estudiadas por el grupo del IFICSIC. Las especies de levadura encontradas con alto poder fermentativo fueron Saccharomyces uvarum, S. cerevisiae y S. bayanus. Las de poder fermentativo medio fueron $S$. capensis, $S$. kloeckerianus y $S$. veronae; y las de bajo Hansenula anomala, Candida valida, C. lusitaniae, Metschnikowia pulcherrima, Kloeckera apiculata, Sporobolomyces pararoseus, Pichia etchellsii, Pichia membranaefaciens, P. farinosa y Trichosporum pullulans. Predominaron las levaduras no esporígenas y de bajo poder fermentativo, en comparación con otras regiones vitivinícolas estudiadas. Las especies más aisladas fueron $K$. apiculata y $S$. cerevisiae, típicas en primera y segunda fase de mostos españoles. Resultó curioso para los autores del estudio el aislar cepas de esta especie en la tercera fase de la fermentación, algo inusual en otros estudios ya realizados, y explicable dada la lentitud de la fermentación vínica en las bodegas. También fue de destacar la presencia abundante de Metschnikowia pulcherrima, y se encontró por primera vez en mosotos españoles $P$. farinosa.

Las microbiodiversidad de las levaduras, entendida como variedad de especies de levadura presentes, fue más abundante en la primera fase, donde predominaron las especies de bajo poder fermentativo, que además son las menos alcohol tolerantes. Desde un punto de vista ecológico, este hecho puede tener sentido si admitimos que las condiciones abióticas del mosto son menos restrictivas que las del vino: existe en él más alimento y menos etanol, que ejerce un efecto antimicrobiano que aumenta progresivamente, a medida que avanza la transformación del mosto en vino.

Consecuencia de dicho estudio fue la obtención de cuna colección de levaduras gallegas, algunas de las cuales todavía se conservan hoy, y se utilizan para llevar a cabo estudios de vinificación mediante contratos de investigación con empresas. Presentan la peculiaridad de ser levaduras aisladas en una época en la que no se utilizaban levaduras alóctonas en forma de levadura seca activa, como se hace en la actualidad. Por ello siguen siendo de enorme interés, y constituyen un patrimonio de la preservación de la microbiodiversidad muy importante al que ha contribuido el CSIC de forma determinante durante los 70 a ños de funcionamiento. 


\section{CARACTERÍSTICAS FÍSICO-QUÍMICAS DE LOS MOSTOS Y VINOS DE GALICIA}

Pero si importante resulta en el estudio del vino todo lo relacionado con su microbiología, no lo es menos el de sus características químicas. Para ello fue llevado a cabo en el IFI-CSIC tan sólo un año después, la caracterización físico-química. Se incluyó también en el estudio la observación microscópica de los sedimentos aparecidos en los vinos, una vez terminada la fermentación. Las muestras estudiadas provinieron de las mismas comarcas que en el estudio microbiológico ya comentado, y probablemente de las mismas muestras de aquel: El Ribeiro y El Salnés (Albariño) (Tabla 2). Macroscópicamente se observó color y brillo, características de la fase visual del análisis sensorial o cata de los vinos, tras de lo cual los vinos fueron degustados, y se procedió a su centrifugacióy al estudio microscópico de su sedimento, anotando forma, tamaño y modo de agrupamiento de los microbios observados. Es estudio del sedimento es importante ya que permite entender la analítica química del vino, y si en alguna variable ha podido intervenir o no la microbiota presente. Se determinaron el etanol, os polialcoholes, el pH, ácido láctico, acidez volátil y total, cenizas, sales, sustanias volátiles neutras, azúcares, compuestos fenólicos e hidroxiácidos. Las conclusiones a las que llegaron los autores fue a la existencia de defectos perceptibes tanto por el análisis sensorial como por el químico. Se encontraron muestras con una elevada turbidez, consecuencia de una mala práctica enológica de clarificación, operación que se ejecuta tras la terminación de la fermentación, y mediante la cual el vino adquiere su brillo y limpidez característicos. También se encontraron vinos con un color alterado, fenómeno éste atribuible por los autores a una excesiva sulfitación de los vinos, operación ésta que se efectúa para disminuir la actividad microbiana indeseable y para estabilizar microbiológicamente al vino. La observación microscópica de los vinos permitió encontrar bacterias presuntamente lácticas, que pueden llevar a cabo tras la alcohólica la fermentación maloláctica, que transforma el ácido málico en láctico permitiendo así obtener energía a los microbios que la realizan. También se detectaron bacterias acéticas, causantes del avinagramiento o acetificación del vino, defecto que se detectó sensorialmente precisamente en una de las muestra de vino estudiadas. Se detectó en algunas muestras una elevada y prohibitiva concentración de cobre, metal pesado indicio según los autores tanto del empleo de materiales inadecuados para la alimentación en la elaboración del vino, como del uso masivo de fungicidas durante el cultivo de la vid.

Concluyeron los autores del estudio que el masivo empleo de antisépticos (funguicidas y sulfuroso) que causó alteraciones organolépticas en los vinos, sería evi- 
table si se empleaba un control microbiano de la fermentación, mediante la inoculación tanto de bacterias para realizar la fermentación maloláctica, como levaduras para llevar a cabo la fermentación acohólica. También recomendaban la renovación de la maquinaria de las bodegas, para evitar contaminaciones de cobre, y posibilitar una mayor higiene en el procesado.

\section{GALICIA Y LA TEORÍA ECOLÓGICA DEL VINO}

Los estudios comentados se enmarcan dentro de la línea de investigación científica en microbiología enológica desarrollada en el Departamento de Microbiología del IFI-CSIC por el grupo de Iñigo, que permitió la propuesta de la denominada Teoría Ecológica del Vino. Según ella, y en palabras del propio Iñigo, el vino ha de ser considerado un proyecto natural único para el hombre, en el que se suceden el tramo geobotánico, que se inicia en el suelo, pasa por la variedad de vid y produce el fruto, y otro tramo microbiológico, que teniendo su inicio en la microbiota epifítica de la uva, origina la transformación de mosto en vino. Para esta teoría, una comarca vitivinícola es un ecosistema, en el que viña y microbiota constituirían la biocenosis, condicionando la aclimatación de la viña la microbiota epifítica de la uva. El mosto en fermentación espontánea seria un subsistema, que produciría un vino ecológico y daría pleno significado al fundamento de la denominación de origen, vigente en la actualidad. La forma en la que desde la microbiología se podría perpetuar este sistema pasa por conocer la sucesión de las especies y cepas de la fermentación espontánea, todo lo cual sería utilizado para obtener un vino estable sin la intervención de moléculas químicas extrañas, tales como los funguicidas o el sulfuroso, que hemos visto se utilizaban profusamente en Galicia en la época en la que se realizan los estudios comentados. Dicho en otras palabras, si se ha conseguido identificar un vino propio de Rioja, otro de Montilla, un Ribeiro o un Albariño se debería al hecho de que tales vinos han sido producidos combinando los tramos geobotánico y microbiológico. En el caso de éste último, y dado que ha primado la fermentación espontánea del vino sin inoculación de cepa alguna, el esfuerzo biotecnológico por conservar dicha cultura enológica ha de ser el de reproducir las sucesiones microbianas, más que el de someter la vinificación a la incorporación de microbios ajenos a la misma.

En términos generales, en el proceso de vinificación espontánea y según la teoría ecológica del vino, se sucederían dos etapas: una anaeróbica y la otro aeróbica. En la primera habría una fase inicial, dominada por especies del género Kloeckera, predominando en España en zonas frías la especie $K$. apiculata, especie eurionica 
que en zonas cálidas (salvo precisamente en La Mancha) se asociaría a Hanseniaspora guilliermondii, y en zonas húmedas con variación de temperatura Candida pulcherrima. En la segunda fase la especie eurionica sería Torulaspora rosei, acompañada en zonas cálidas con baja humedad ambiental por Zygossaccharomyces veronae, y en el Penedés por Torulaspora bacillaris. En la tercera fase predominaría la especie eurioica Saccharomyces ellipsoideus, que puede presentarse asociada como especie esrenotérmica a $S$. pastorianus en zonas frías, y a $S$. mangini y $S$. oviformis como especies estenotérmicas en zonas cálidas. En la fase aeróbica posterior, en zonas cálidas y vinos de elevado grado alcohólico, que no es el caso típico de los vinos de Galicia, dominarían especies del género Saccharomyces como $S$. beticus, $S$. cheresiensis, $S$. rouxii y $S$. montuliensis, que en zonas con contenido alcohólico limitado se verían acompañadas tanto por especies esporígenas tales como Hansenula anomala, Z. acidifaciens y Pichia membranaefaciens, y asporígenas tales como C. microderma, Criptococcus laurentii y Rhodotorula glutinis. Favorecer la reproducibilidad de estas sucesiones, más que utilizar especies extrañas de levadura seca activa y empleo masivo de antisépticos como el sulfuroso, molécula tenida como "panacea" por muchos enólogos para realizar el control microbiano de las fermentaciones, eso sí, con el empleo de cepas de levaduras comerciales alóctonas de la región en cuestión, serían garantías para preservar el tipismo de los vinos españoles, según la propuesta de la teoría del vino ecológico.

Mediante la aplicación de cepas autóctonas, tanto de levaduras como de bacterias, se pasaría del vino tecnológico al vino ecológico, de la fermentación alcohólica, más preocupada por la obtención de un grado alcohólico con el que se estabilice rápido el vino, a la fermentación vínica, en la que para obtener la riqueza de matices sensoriales perceptibles en la cata habría que potenciar la actuación de una sucesión de especies de levaduras y bacterias autóctonas de cada comarca que, aun siendo de la misma especie que las de otra comarca vitivinícola, no estarían tan adaptadas a la misma. Al mismo tiempo se realizaría de modo más higiénico la vinificación, permitiéndose así la disminución en el empleo de funguicidas y la aplicación del sulfuroso, y potenciando la acción de la naturaleza.

Si lo observado en los estudios realizados por el grupo de Iñigo era una sucesión microbiana, eso era lo que habría que intentar reproducir siempre, mediante el uso de una nueva biotecnología de fermentación vínica. S evitaría de este modo la falta de concentración inicial de levaduras que p.ej.- se veía como causa de enlentecimiento de la vinificación en las bodegas de Galicia estudiadas. La limitación de la sulfitación en el mosto, utilizada para acabar con las levaduras de primera fase, permitiría el empleo del denominado "mosto integral", con todas las especies inoculadas que de modo natural crecerían en condiciones idóneas en cada denominación de origen. 
La época en la que se fragua la teoría ecológica del vino es un momento en el que se ha realizado la institucionalización de la ciencia de la ecología en España, y precisamente en el CSIC. El entonces secretario general de dicho organismo, el Prof. Jose María Albareda, experto en la ciencia dedicada al estudio de los suelos, tan importante en viticultura, llamada edafología, fue el principal promotor del desarrollo de la ecología española. El que es considerado pionero en la misma, el hidrobiólogo Celso Arévalo, acabó investigando en el CSIC, donde también lo hicieron el mayor ecólogo español de todos los tiempos, Ramón Margalef, y Fernando González Bernáldez, Pedro Montserrat, Pedro Bacells y un largo etcétera. Además sería el Prof. Albareda quien crearía en 1942 la primera institución española que incluiría la palabra ecología en su nombre, que no sería otra que el Instituto de Edafología, Ecología y Biología Vegetal del CSIC, denominado en la actualidad Centro de Ciencias Medioambientales.

La aplicación de la Teoría ecológica del Vino llevó a la puesta en el mercado del que se denominó Vino Ecológico, elaborado en una bodega de la Denominación de Origen Rueda. Gracias a los estudios microbiológicos de Iñigo sobre el vino, fue creada la colección de Levaduras del Instituto de Fermentaciones Industriales del CSIC, en su día la mayor existente en España, de la que todavía se custodia parte en el Departamento de Microbiología del mencionado instituto, y con la que se siguen llevando a cabo estudios científicos para transferirla a empresas del sector. De dicho departamento han salido algunas de las que probablemente deban considerarse más importantes obras escritas sobre microbiología enológica española. Recientemente se ha publicado la primera patente para el empleo de la levadura Saccharmomyces cerevisiae TG-CSIC en la vinificación de albariño, como consecuencia de un estudio llevado a cabo en dicho departamento.

\section{BIBLIOGRAFÍA}

BÁGUENA, Mª J. (1984), "La microbiología en los artículos de revistas y comunicaciones a congresos de medicina del siglo XIX español”, Rev. Esp. Doc. Cientif. 7, 29-38.

BÁGUENA, Ma J. (1988), "Luis del Río y Lara y la constitución de la microbiología médica en España”, Asclepio 40, 375-392).

BÁGUENA, Ma . J. (1984), "La microbiología en el siglo XIX español: organización de su actividad científica”, Med. Esp. 83, 180-183

BRAVO, F. (1995), “Del vino y otros temas”, EYPASA, Madrid.

CARRASCOSA, A.V. (2007), "El Instituto de Fermentaciones Industriales y la microbiología enológica española", Sem. Vitivin. 3169, 1371-1375 
ID., A.V. (2007), “Los orígenes de la microbiología enológica española”, Sem. Vitivin. 3162, 809-813

ID., A.V. (2008), “Juan Marcilla: presidente fundador de la SEM”, Actualidad SEM 45, 16-21

ID., A.V. (2009), "Isabel Toran: enóloga pionera", Sem. Vitivin. n 3261, 42

ID., A.V. (2009), "La nueva levadura de uva albariño permite aumentar la calidad del vino", Diario GLOBAL HENARES/ALCALÁ, Sección COMUNIDAD DE MADRID, 5/3/2009, pp. 10-11

ID., A.V. y Martínez, C.(2009), "Levadura ecotípica para albariño", Tecnología del Vino (En prensa).

ID., A.V., Martínez Rodríguez, A.J.,Cebollero, E., Núñez, Y., León, A., Martínez, C. y Rodríguez, E. (2008), "Procedimiento para la obtención de vinos de la variedad de uva albariño (y otros) con alto contenido aromático, mediante el uso de una levadura ecotípica”, No de Solicitud: P200801500. Fecha de Presentación: 22 de Mayo de 2008.

ID., A.V., MUÑOZ, R. y GONZÁLEZ, R. (2005), "Microbiología del Vino", AMV Ediciones, Madrid.

CASTELLI, T. (1953), "Gli agente Della fermentazione vinaria", Riassunti delle Comunicazione, Volume III, Sezioni XVII-XXII, 902, 161-162.

ID., T. e IÑIGO, B.(1958), "Los agentes de fermentación vínica en la Región Manchega y Zonas Limítrofes", Ann. Fac. Agra. Univ. Perugia. Vol. XIII, 1-17.

CSIC. Memorias Institucionales 1940-1970. www.csic.es. CSIC, Madrid.

IÑIGO, B. (1991), "Tommaso Castelli e lo sviluppo della microbiologia enologica", Atti Academia Italiana Della vite e del vino 423-430

ID., B. y BRAVO, F. (1977), "Estudio de mostos y vinos de Galicia”, A.T.A. 17, 268-276.

MARCILLA, J., ALAS, G. y FEDUCHY, E. (1939), "Contribución al estudio de las levaduras que forman velo sobre ciertos vinos de elevado grado alcohólico", Anales del Centro de Investigaciones Vinícolas Vol. I, nº 1, 1-230

QUECEDO, C.R., SOMAVILLA, J.F., ARROYO, V. e IÑIGO, B. (1976), “Agentes de fermentación de mosto de uva de la zona de Galicia", A.T.A. 16, 1, 123-130.

SUAREZ-LEPE, J.A. e IÑIGO, B. (1988), "Microbiología enológica”, Ed. Mundi-Prensa, Madrid. 